\title{
ESTUDIO DEL TEXTO DE AL-IDRISI SOBRE ALICANTE
}

\author{
Por \\ MIKEL DE EPALZA
}

El geógrafo árabe Al-Idrisi (que termina su obra en 1154) es el escritor más importante para conocer la realidad y la estructura urbana de la ciudad de Alicante en época árabe. Todos los historiadores de la ciudad lo citan, en sus varias traducciones. Se ha traducido de nuevo en esta misma revista (Sharg A/Andalus. Estudios Arabes, núm. 1. 1984, p. 178), al presentar la visita del escritor árabe moderno Shakib Arslán a Alicante, en 1931. Allí también se ve có-

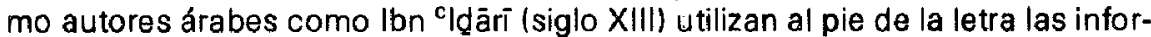
maciones de Al-Idrisi. Aunque hay que situar muy concretamente el texto en la época en que se escribe -entre la caída del imperio almorávide y la conquista de la región alicantina por los almohades - y aunque no hay que generalizar tampoco esas informaciones para todo el período musulmán, de más de cinco siglos en Alicante, el texto es importante y se merece una traducción esmerada.

La traducción que se va a emprender aquí no es una simple traducción del texto (que sólo ocupa 10 líneas en la última edición crítica), sino un estudio de ese texto. Se va a intentar estudiarlo en su contexto, que es el conjunto de la obra de Al-Idrisi. Como libro técnico, de geografia, esta obra utilizá palabras estereotipadas, que aplica a Alicante como a otras poblaciones de Al-Andalus. Una comparación de todos los textos paralelos en los que se utilizan esos términos y de las realidades a las que se aplican puede aportar mucho al conocimiento simplemente lingüístico de las palabras árabes, sacadas del diccionario. $Y$, por supuesto, se revelará mucho más rica que la mera traducción al castellano.

Esta traducción va a ser, pues, un intento de "traducción estudio", con dos instrumentos de análisis: el propio léxico árabe, que no se ajusta siempre al campo semántico de las palabras castellanas por las que se intenta traducirlo, y la comparación con textos paralelos de Al-ldrisi, para calibrar mejor la realidad alicantina descrita por el geógrafo.

En este estudio del texto ni se pretende estudiar todo el urbanismo de Alicante en época árabe - trabajo ulterior - , ni tampoco se van a comparar las informaciones de Al-Idrisi sobre Alicante con las de otros textos árabes ni con otras fuentes (arqueológicas, toponímicas, documentales cristianas, etc.) que se refieren al pasado árabe de la ciudad. 


\section{Al-Idrisi y su obra}

La vida de Al-Idrisi (Ilamado a veces en Europa "El Nubiensem) es mucho menos conocida que su obra. Su nombre completo es $A b \bar{u}^{\circ} A b d$ Alläh Muhammad Ibn Muhammad Ibn 'Abd Allāh Ibn Idris Al-Hammüdí Al-Hasani, llamado también Ǎs-Sarif Al-Idrisí, "el ldrisí noble descendiente del Profeta" (ver artículo de G. OMÁN, "Al-Idrīsī, Encyclopédie de /"s/am, 2. ed., III, 105810611 . Después de muchos viajes -dice expresamente en su obra que estuvo en Algeciras, en Córdoba y en Lisboa, y se puede sospechar que estuvo también en la región de Alicante - se puso al servicio el rey normando de Sicilia, Roger II, para ilustrar un planisferio. Terminó su obra en 1154 y parece que murió hacia 1165 (ver C. E. DUBLER, "ldrisiana hispanica I. Probables itinerarios de Idrīsī por Al-Andalusn, Al-Andalus, XXX, Madrid-Granada, 1965, páginas 89-1371.

Su obra, tanto en su forma completa como en formas abreviadas y traducciones, ha tenido muchos títulos: desde el abreviado "Kitāb Ruyār» (El Libro de Rogerl, hasta el árabe más literario "Kitāb Nuzhat al-muštāq fi jtirāq al-afäq", traducido al latín como "Opus Geographicum sive Liber ad eorum delectationem qui terras peragrare studeant». Ha tenido muchas ediciones, totales o parciales, $y$ numerosas traducciones. Ha sido objeto de innumerables estudios y es continua fuente de referencia para todo el mundo medieval de Europa, Asia $y$ África.

Aquí nos vamos a basar en las dos mejores ediciones: la del siglo XIX de Dozy y De Goeje, con traducción al francés y estudio del léxico (R. DOZY et M. J. DE GOEJE, Description de l'Afrique et de l'Espagne par Edrisi. Texte arabe publié pour la premiere fois d'après les man. de Paris et d'Oxford avec une traduction, des notes et un glossaire, Leiden, 1866; reimpresión, Leiden, 1968), y la edición crítica realizada en Roma y Nápoles, bajo el patrocinio de $E$. Cerulli $y$ otros, por A. Bombaci, U. Rizzitano, R. Rubinacci y L. Veccia Vaglieri lel fascículo $V$, en el que está Al-Andalus, salió en 1975; lo citaremos por el que edita el texto de Al-Andalus, C. E. Dubler, $v$ el de las costas magrebíes vecinas de Al-Andalus, M. T. Petti Suma).

Las traducciones al castellano son muy antiguas, ya en el siglo XVIII [J. A. CONDE, Descripción de España de Xerif Aledris, conocido por el Nubiense, Madrid, 1799; reimpresión, Madrid, 1983). Como la principal dificultad de esta obra ha sido la identificación de los lugares que en ella aparecen, hay que señalar la notable aportación de Saavedra, en el siglo XIX ID. E. SAAVEDRA, "La Geografía de España del Edrisi», Boletín de la Real Sociedad Geográfica de Madrid, X, 1881; XVIII, 1885; XXIII, 1889), Blázquez (A. BLÁZQUEZ, "Descripción de España por Abu-Abd-Allah-Mohamed-al-Edrisi", B. R. S. G. M., XLIII, 1901, pp. 7-51) y Mones (H. MONES, "Al-ŷugräfiya...", Revista del Instituto de Estudios Islámicos en Madrid, IX-X, 1961-62, pp: 257-372, con resumen en castellano de la parte referente a Al-Idrisī, pp. 285-297), en el siglo XX. Dubler, además de emprender la edición crítica que han publicado póstumamente los italianos en el conjunto de la edición de Al-ldrisi, había hecho unos estudios parciales en castellano, que conviene recordar, además del ya citado 1C. E. DUBLER, "Los caminos a Compostela en la obra de Idrīsī", Al-Andalus, Madrid, XIV, 1949, pp. 59-122, y "Las laderas del Pirineo según Idrīsi», A/Andalus, XVIII, 1953, pp. 337-373). Finalmente, el historiador y publicista Antonio Ubieto Arteta reunió ediciones $v$ traducciones de Blázquez, Dozy/De 
Goeje y Saavedra en un volumen titulado Idrisi. Geografía de España IValencia, 19741 .

Hay que recordar que la frecuente mención por muchos historiadores de "Idrisi" es totalmente incorrecta: hay que llamarle con su nombre propio genuino árabe "Al-Idrisi», pónganse o no los signos de vocal prolongada.

Antes de analizar palabra por palabra todo el texto de Al-Idrisi sobre Alicante, se puede presentar ya la traducción completa, tal y como la vamos a establecer, la cual no sustituye ni muchos menos, sino que empobrece, el estudio analítico al que se va a someter el texto árabe.

"Después viene la cora de Tudmir, donde hay ciudades como Murcia, Orihuela, Cartagena, Lorca, Mula y Chichilla. Está contigua a la cora de Cuenca, donde están Orihuela, Elche, Alicante, Cuenca y Segura. La sigue la región de Arguira, donde hay países como Játiva, Júcar y Denia, y muchos castillos." (Ed. Dubler, p. 538.)

"Y desde la ciudad de Denia, antes mencionada, en la costa, hasta la ciudad de Alicante, al oeste, yendo por mar, hay 70 millas.

"Alicante es un ciudad, pequeña, de buenas construcciones. Tiene zoco, mezquita-aljama y otra mezquita con predicación. Exporta esparto a todos los países del mar. Hay muchas frutas y legumbres, higos y uvas. Tiene una alcazaba, muy inasequible y elevada, en lo más alto de un monte, al que se sube con fatiga y cansancio. En ella, a pesar de su pequeñez, se construyen naves para largos viajes y barcazas. Cerca de esta ciudad, hacia el oeste, hay una isla llamada Planesa. Está a una milla de la costa. Es un buen fondeadero, que puede servir a las naves del enemigo. Está frente al Promontorio del Observatorio. Desde el Promontorio del Observatorio a la ciudad de Alicante hay 10 millas. Desde la ciudad de Alicante, por tierra, a la ciudad de Elche hay una jornada escasa. Desde la ciudad de Alicante a las gargantas de Palos hay 57 millas." (íd., 558.)

\section{El tamaño de la ciudad: "una ciudad pequeña", pero...}

Lo primero que afirma Al-Idrisi de Alicante, como de otras poblaciones de Al-Andalus, es que es "una ciudad pequeña» (madina șagïra). Más adelante insistirá: "hay que decir también que a pesar de su pequeñez..." tiene atarazanas para la construcción de barcos (wa-hiya aidan maca sugri-hă...). El abstracto "pequeñez" (șugr) o el adjetivo "pequeñola" (sagîr/a) tienen el mismo campo semántico que en castellano. Pero quizá puede determinarse algo su significado aplicado a la ciudad de Alicante en el siglo XII viendo cómo lo aplica AlIdrisi a otras poblaciones de Al-Andalus y viendo qué otros adjetivos de tamaño èmplea para calificar a las ciudades.

En Al-Andalus las poblaciones calificadas de upequeñas" son numerosas. Unas son de tierra adentro, como Daroca, Lérida, Cuenca, Úbeda led. Dubler, pp. $554,554,560$ y 569 , respectivamente). Otras son costeras, más parecidas a Alicante, como la alquería de Adra (Almería) (qarya cadra madina sagira), Marbella, Ibiza, Tarifa, Huelva (ed. Dubler, 564, 570,582, 539, 541 ). Dos ciudades "pequeñas" nos parecen significativas: Madrid, calificada de uciudad pequeñan con una fortaleza bien pertrechada y construida lqa $F_{a}$ munfa $m a^{c} m u ̈-$ ra) (ed. Dubler, 552) y el puerto magrebíde Honéin, al oeste de Orán, que en el 
siglo XII era muy importante por ser el de salida de la región de Tremecén y de rutas del Sáhara asi como puerto de la región de origen familiar de la dinastía almohade. Al-Idrisi describe Honéin de forma parecida a Alicante: «es una ciudad hermosa y pequeña, junto al mar; bien construida; la domina una muralla fuerte; tiene mercados donde se compra y se vende; fuera de la ciudad hay zonas cultivadas abundantes y poblaciones agrícolas muy concentradas" (trad. de ed. M. T. Petti Suma, p. 5341.

El adjetivo "pequeña" aplicado a una ciudad contrasta con los de "grande" (kabira) o "mediana" (mutawassita). En Al-Idrisi son "grandes" Sevilla, capital del Al-Andalus almohade; Almería, en su tiempo destruida por los cristianos; Carmona (Sevilla), cuyas murallas son comparables a las de Sevilla; Palma de Mallorca (madina kabira) y Talavera (ed. Dubler, 541, 563, 572, 582, $551)$. Las ciudades calificadas de "medianas» son Chinchilla, Huete, Uclés, Almonacid de Zorita, Almuñécar, Guadix, Baza, Jerez, Faro, Melilla, Niebla, Alcácer do Sal led. Dubler, 560, 560, 560, 561, 564, 567, 567, 572, 543, $533,541,5441$. Varias de estas ciudades son calificadas de una forma más completa: "de mediano poder" (mutawassiat al-qadr o al-miqdär), lo que indica que la calificación de las ciudades por el tamaño no se refiere tanto a la superficie o a la población, sino a una categoría global que apreciaba la potencia de una ciudad. Por supuesto que un pueblo no podía llegar a esa categoría: se nos dice de un "pueblo grande" al sur de Tánger que es "como una pequeña ciudad" (qarya kabïra ka-l-madina aș-șagïra) y se recuerda que antes fue ciudad con muralla y zocos, pero que ahora está arruinada (ed. M. T. Petti Suma, 5311 .

Por eso es significativo no sólo que se dedique a Alicante tantas informaciones, sino que se haga notar que, a pesar de su pequeñez, tiene atarazanas para la construcción de naves. Esta clase de reserva sólo se advierte al describir a Priego de Córdoba (ed. Dubler, 571): «es una ciudad de pequeño poder (sagirat al-qadrl..., pero es extremadamente hermosa por la cantidad de agua que tiene....". Semejante salvedad se hace también de otra "ciudad pequeña" del norte de Marruecos, en la que uhay zocos, en la medida de su poder falà qadri-hā) donde se compra y se vende; tiene muchos recursos" (ed. M. T. Petti Suma, 5301.

Como tampoco esos tres calificativos de "pequeña", "mediana» o "grande" se emplean para todas las poblaciones de Al-Andalus descritas por Al-idrisi, quizás no hayan de considerarse como categorías muy especificantes, sino como un juicio global sobre la importancia de una ciudad, antes de entrar en sus características particulares.

\section{La importancia de ser una ciudad}

El hecho de que Al-Idrisi llame a Alicante "ciudad" (madína) es, quizá, lo más importante que puede decir de esa población. En efecto, la "ciudad" supone para la lengua y la cultura árabes una calificación específica de una población, con todas las estructuras que le son propias y que no se puede desarrollar enteramente en el marco de este estudio de texto, si no queremos convertirio en un tratado de urbanismo árabe.

Dozy define muy bien los dos sentidos que tiene esa palabra, en su relación con otras entidades geográficas o en su estructura interna: es la capital de un distrito, de una provincia, de una isla o de un reino, y es también la parte 
más antigua o central de una ciudad (por oposición a un arrabal) (Supplément, II. 583). En Al-Idrisi se califican las poblaciones generalmente como fortalezas (hisn) o como ciudades (madina): hasta se dice de Cabra (Códoba) que es una "fortaleza" grande como "la ciudad" (wa-hișn qabra kabir ka-l-madina) (ed. Dubler, 571 ). Tampoco una alquería podrá ser comparada a una "ciudad", como va se ha visto. Aunque se trate de grandes capitales, como Córdoba, Zaragoza o Valencia en el siglo Xli, que Al-Idrisi califica sin referencia al título de "ciudad", el modelo urbanístico es idéntico. Sólo las ciudades tienen la plenitud de la vida cívica, con sus principales elementos: mezquita aljama, 'baños, comercios, magistratura, autoridades administrativas, enseñanza, etcétera.

Alicante en el siglo XII es calificada por Al-Idrisi como "ciudad", como lo habia sido ya en el VIII, según los textos que se nos han conservado del pacto de Teodomiro. Eso debería confirmar que mantuvo siempre esa calificación, a pesar de las pocas referencias que tenemos de ella en los más de cinco siglos de gobierno musulmán.

Las "ciudades" según Al-Idrisi son calificadas no sólo por su tamaño -- "pequeña", "mediana", "grande"-, sino también con otros adjetivos, de los que los más frecuentes suelen ser "hermosa, buena, sana" (hasana), "muy poblada" (ähila), "próspera, de enraizada vida urbana" (mutahadudira) y sobre todo "con buenas construcciones" (Cämira). El hecho de que a Álicante sólo se le aplique este último calificativo, cuando en otros casos va acompañado de alguno más, puede ser significativo.

\section{Una ciudad «con buenas construcciones»}

Se ha traducido el calificativo que hace Al-idrisi de Alicante como "con buenas construcciones" Càmiral, pero el término árabe es más complejo $y$ plantea algunos problemas de significación.

Kazimirski, en su diccionario, pone los siguiente significados: habitado, poblado, cultivado, en estado de cultivo ly no salvaje, arruinado y abandonado), próspero, floreciente, en buen estado, bien provisto (Kazimirski, II, 365). El glosario de Al-Idrisi de Dozy y de Goeje (p. 345) se limita a señalar que se puede decir también de un mercado o zoco, pero Dozy suele traducir este término como "muy bien poblado", "bien habitado".

Probablemente, el significado de la palabra, para Al-ldrisi, englobe todas estas ideas, donde la relación entre la población y el cuidado urbanístico de los edificios está subyacente. De hecho, se aplica muchas veces a castillos-fortalezas (hisn): a los de la región entre Jaén, Baza y Guadix, como Jódar, de los que se diçe que son numerosos, "de buenas construcciones" (cāmira), "semejante a ciudades" (mumaddana), "muy pobladas» (āhila) y que tienen toda clase de productos; entre Málaga y Córdoba (al-hușün a/-cämira), que son capitales de esa región; el gran castillo de Caudete de Córdoba (kabir ${ }^{c} a \operatorname{mir}$ ); el de Cutanda en Aragón "hermoso, monumental, de construcción perfecta" (hiṣn hasan katür al-jalq cămir bi-dāti-hil; Bocairente, "de buena construcción, como la ciudad" (hiṣn... 'āmir ka-l-madinal; Segura de la Sierra, también "de buena construcción, como la ciudad"; Peñíscola, "castillo... de buena construcción y bien poblado" (hiṣn... "ämir ähill, al igual que Constantina (Sevilla); Belicena (Granada) que es "ciudad" pero también "un castillo grande, de buena construcción, con buena defensan (ḥiṣn kabïr āmir la-hu ḥiṣāna) (ed. Dubler, 569, 570, 571. 
$556,557,560,555,574,573)$. En todos estos casos en que el calificativo se refiere a castillos-fortalezas el que vaya con "bien poblado" (ähill) y "grande" (kabir) o "buena defensa" (hișāna, o el mismo término de hiṣn) parece indicar que señala otra cualidad, el del buen estado y calidad de la construcción o del edificio o edificios.

Ese calificativo se aplica también a ciudades: Valencia (càmirat al-quțr), Burriana (Castellón), Denia, Málaga, Baza, Evora ('ầmira bi-n-năs) (ed. Dubler, $556,557,565,568,544)$. En este último caso Dozy traduce "bien poblada" (p. 219), pero eso no excluye tampoco el sentido de las construcciones.

También se califican como "de buenas construcciones" (càmira/ unos mercados o zocos, como los de Trujillo, Écija y Baza (ed. Dubler, 550, 576, 568), - arrabales, como los de Denia, Murcia y Almería led. Dubler, 557, 559, 5631, o pueblos o alquerías, como los de Valencia, que pasan de 8.000, o los que están entre Burriana y Murviedro-Sagunto, o unos al sur de Tánger led. Dubler, 556, 556, 5301. También se califica de "con buenas construcciones" ('ámira) a unos terrenos de cultivo (mazáric) en La Mancha, en la región de Huete y Uclés (ed. Dubler, 560 ).

Por eso, aunque el término no quede aún todo lo preciso que sería de desear, se puede afirmar que, aplicado a Alicante, significa que es ciudad de hermosos edificios, sin ruinas, cuidados por una población numerosa - relativamente - y activa.

\section{Una ciudad comercial: el zoco o mercado}

Después de calificar a Alicante como "ciudad, pequeña y con buenas construcciones". Al-Idrisi dice que "en ella hay un zoco" (wa-bi-hā süq) (ed. Dubler, 558).

Esta afirmación tan escueta no se encuentra para ninguna otra población de Al-Andalus. Generalmente se dice en plural o/y acompañado de un calificativo: hay "zocos permanentes" (aswãq qā'ima) en Alpuente y Albarracín (ed. Dubler, 553); «zocos bien construidos» en Écija, Trujillo y Málaga (íd., 550, 572 , 565 ); "buenos zocos" (hasanat al-aswāq) en Alamín, cerca de Madrid (íd., 553); "zocos bien provistos" (murattabat a/-aswāq) en Silves, o "zocos de hermosa ordenación” (aswāq yamillat at-tartïb) en Talavera (íd., 543, 551). Se dice sencillamente que hay zocos, en plural, en Berja, Baeza, Valencia, Orihuela, Elves y Elche (íd., 563, 569, 556, 558,550, 557). De Lorca se afirma que tiene zocos y que su arrabal tiene un "zoco de los perfumes" o de productos olorosos (süq al-`atar) (íd., 561 ).

En singular, sólo se dice que tiene "un zoco famoson (süq mašür) de Bocairente, Caudete de Córdoba e Iznajar, cerca de Archidona (íd., 557, 571 y 5711. Lo de "famoso" no indica la importancia de ese mercado, sino más bien la fama por un determinado producto, como son los tejidos para Bocairente.

El estudio comparativo nos da, pues, que Alicante no tenía más que un solo "zoco o mercado", sin la variedad de otras ciudades, que tenían mercados diversos, con distintas especialidades o en barrios diferentes. Esto corresponde a la pequeñez general de la ciudad, que concentraba la compra y venta de todos sus productos comerciales en una sola calle o zoco. 
Por otra parte, el tener un zoco o mercado - generalmente de productos no perecederos, en lengua árabe-corresponde a la categoría de la ciudad, capital de región y puerto con relaciones de in tercambio marítimo y terrestre. También indica una artesanía local, que transforma los productos y los vende en el mismo zoco, sea a habitantes de la ciudad y sus alrededores, sea para la exportación por tierra y por mar.

Todas estas funciones de compra $y$ venta indica la afirmación de Al-ldrisi de que en Alicante "hay un zoco o mercado", en términos generales. A continuación especificará un poco más las operaciones comerciales más originales que se realizan en la ciudad: exportaciones de esparto, producción agrícola, construcción de naves.

\section{Importancia administrativa de sus dos mezquitas}

Al-Idrisi afirma también que en Alicante hay dos mezquitas, al pie de la letra «una mezquita aljama y un púlpito" (masŷid yàmıc wa-minbar).

La lectura escueta de esta información, sin un ejercicio de comparación, puede inducir a error. En efecto, el mímbar es el púlpito en forma de escalera que está a la derecha del nicho principal (o mihrab) de la pared de orientación de la mezquita o qibla. Desde él se realiza la predicación de la oración musulmana del viernes al mediodía, a la que los musulmanes de una ciudad tienen que asistir obligatoriamente. Esta predicación y oración sólo se realiza en la "mezquita mayor" o mezquita aljama, por lo que afirmar que ésta tiene un mímbar o púlpito parece reduplicativo. Por otra parte, afirmar de una población que tiene mezquita mayor con púlpito es una información aparentemente irrelevante, ya que la reunión del viernes es una obligación fundamental del Islam y tener la mezquita para ello parece una realidad esencial del urbanismo musulmán, aun en la más modesta población de Al-Andalus y ciertamente en todas las que se tienen que citar en la obra de geografía de Al-idrisi. De ahí la sospecha de que si se dice de una ciudad que tiene "una mezquita aljama y un púlpito", como se dice de Alicante, es porque asi se afirma una realidad especial, que no tienen todas las poblaciones musulmanas de Al-Andalus.

Dozy, al traducir el texto de Al-ldrisi, pudo darse cuenta de esa realidad, al tener presente un número significativo pero limitado de ejemplos: en Lucena hay una mezquita-aljama en el arrabal donde viven los musulmanes (en el centro de la ciudad viven judíos) (íd., 571); en Córdoba hav una incomparable mezquita-aljama (íd. . 575); en Jaén hay una mezquita-aljama y personajes nobles y sabios (íd., 568); en Madrid, cuando aún era musulmana, había una mezquita-aljama y una predicación de altura (wa-jutba qã 'ima) (id., 552), igual que en Almería cuando aún no estaba en poder de los cristianos Imasŷid ȳâ$m i{ }^{c} j$-hā qāim bi-dāti-hi) (íd., 566). Pero ya en Almería afirma Al-Idrisi que utiene mímbares, entre elios la ciudad de Berja y Dalias", cuyas distancias entre ellas y con Almería menciona (wa-li-l-Maraya manābir min-hä madina Barŷa wa-Dalàya) (íd., 563). También afirma que tiene mezquita-aljama y mímbar, al igual que Alicante, la ciudad de Alamin (Al-Fahmin), entre Madrid y Guadalajara (íd., 553). De Santa María del Algarve (ahora Faro, al sur de Portugal) dice que tiene una mezquita-aljama, un mímbar y un "ugar de reunión" yamācal (id., 543).

De lo limitado de la lista de menciones de mezquitas-aljama y de mímbares ya sospecha Dozy que sólo se mencionan cuando tienen una peculiaridad es- 
pecial, especialmente en relación con los mímbares. Del ejemplo de Santa Maria del Algarve y de otros textos orientales y magrebies deduce que se trata de tres clases diferentes de mezquitas: "mezquita catedral" o mayor; "mezquita parroquial» o menor; "mezquita privada" (en el léxico de su traducción dés AlIdrisi, pp. 279-280). En el diccionario general, Dozy ya saca las consecuencias de todas las menciones del mímbar en Al-Idrisi: éste tiene un sentido más amplio que el de "púlpito" y ha de traducirse como "mezquita, dependencia, parroquia, distrito" (Supplément, II, 643-644), que es como traduce las menciones del mímbar en el texto, incluso en la cita sobre Alicante ( «une mosquée cathédrale et une mosquée paroissiale", /. c., p. 235). El ilustre arabista holandés acierta plenamente en su descripción de la realidad explicitada por Al-Idrisi en Al-Andalus, pero parece desconocer en parte las funciones de las mezquitas en el Islam y la legislación que gobierna sus fundaciones. Tampoco el uso de la terminología cristina - catedral, parroquia, oratorio - es la más adecuada para explicar los términos de mezquita-aljama, mímbar y yamāca.

En efecto, la «mezquita mayor» de una población no sólo tiene una función religiosa de piedad - oración y predicación - sino de reunión política de todos los responsables, autoridades y personajes de la ciudad. Por eso sólo pueden reunirse en una mezquita, la mezquita-aljama, "la que reúne» (ŷāmi ${ }^{c}$ ).

Cuando la ciudad es muy extensa y la distancia de los barrios a la "mezquita mayor" es muy grande, se permite que haya predicación en otra mezquita (es decir, que haya mímbar), aunque la mezquita de las autoridades sea siempre única, la mezquita-aljama. La legislación musulmana es tan estricta al de-

Cuando la ciudad es muy extensa y la distancia de los barrios a la «mezquita mayor" es muy grande, se permite que haya predicación en otra mezquita (es decir, que haya mímbar), aunque la mezquita de las autoridades sea siempre única, la mezquita-aljama. La legislación musulmana es tan estricta al determinar las distancias y condiciones para que haya mezquitas con mímbar en una misma ciudad, que se ha podido tomar esas normas para establecer el aumento demográfico de una ciudad, a partir de las fechas de establecimiento de sus diversas mezquitas con mímbar: así to ha estudiado para Túnez el historiador y arqueólogo Abdelaziz Daoulatli, actual presidente dle ICOMOS.

Así se explica la mención específica de Al-Idrisi -y de otros textos medievales, como el de Al-Ya ${ }^{C}$ qübi cuando dice que en el distrito de Tudmir no hay más que dos mímbares, en Lorca y Al-cAskar - cuando afirma que en Alicante y otras ciudades hay una mezquita-aljama y un mímbar. Afirma así que "además de la mezquita mayor donde se reúnen las autoridades el viernes, hay otra mezquita en un barrio suficientemente distante, para que esos habitantes puedan asistir a la predicación sin tener que hacer un largo desplazamiento o porque la mezquita mayor es tan pequeña que no caben en ella todos los habitantes de la ciudad". Todo ello quiere decir la doble mención de la mezquita-aljama y el mímbar o púlpito.

Se trata, pues, de una mención de tipo urbanístico. La segunda mezquita con mímbar de Alicante estaría en el arrabal o Vila Nova, estudiado por Màrius Bevià, es decir en el actual barrio de la iglesia de San Nicolás.

Al-Idrisi indica así una peculiaridad de Alicante. Pero también afirma así la importancia de las mezquitas en la sociedad y el urbanismo musulmanes. Expli- 
citar sus funciones sería demasiado largo y no corresponde al alcance que quiso dar a esa mención el autor del texto que aquí se traduce, comenta y estudia.

\section{La exportación de esparto}

Después de haber calificado la ciudad - pequeña y con buenas construcciones - y de haber señalado su rango urbanístico - es una ciudad y tiene dos mezquitas para la predicación-, Al-Idrisi va a señalar su producción comercial específica, to cual no excluye, evidentemente, otros productos comerciales más generales en la sociedad andalusí.

Empieza diciendo que "de ella se exporta el esparto a todos los paises del mar" (wa-yatầahhazu min-hä bi-thalfä' ilà yamí bilād al-bahr). Para comprender bien el alcance de esta afirmación, conviene analizar filológicamente sus términos y compararlos con otras afirmaciones semejantes que hace AlIdrisi de otras poblaciones y regiones de Al-Andalus.

El verbo «exportar» (vataŷahhazu) significa también y simultáneamente "proveerse, hacer provisiones". A ese doble sentido corresponden las dos preposiciones que rige en la frase: se exporta hacia (ila) y se proveen de (bi-) (Dozy, Supplément, 1, 228; Kazimirski, 1, 3441. Si sólo se tratara de "exportar" se utilizaria el verbo de la raíz "saçar" (istajraya), que Al-Idrisi utiliza para el coral de Ceuta "que se exporta a todas las regiones de los mares" (al-muryaan al-mustajray bi-yamî́ aqtār al-bihàrl. Pero de ese mismo coral, al hablar de su elaboración en los zocos o mercados de Ceuta, dice como de Alicante que "se exporta y se provee" (yatayahhazu) a los demás países, especialmente a Ghana y a los demás países del Äfrica negra, porque alií se utiliza mucho. Emplea también el verbo "se lleva hacia" (yuhmilu ilà) (ed. Dubler, 529). De Ceuta y su región dice también que "se exporta y se provee" (yatayahhazu) ella misma de la abundancia de sus frutos lid., 528). Con el ejemplo ceutí tenemos una gama importante de significados afines al de al afirmación de Al-ldrisi sobre el esparto de Alicante.

Según Al-Idrisi, también "se exporta y se provee" de aceite "al extremo de Oriente y de Occidente, por tierra y por mary, a partir de Sevilla y su región (yatayahhazu bi-hi min-hā ilà aqșà al-mašāriq wa-l-magārib barran wa-bahranı (id., 541). También de las montañas del Sistema Central, al norte de Madrid, se exporta (vatayahhazu) su excelente carne de ganado "a los otros países" (ilà sā'ir al-biläd), va que es muy famosa "en todas las regiones de Al-Andalus" (fi yamī aqtār Al-Andalus ) (íd., 552). También de Guadalajara "se exporta" y "se lleva" (yatayahhazu bi-hi min-hä wa-yuhmalu) el azafrán "a las demás provin-

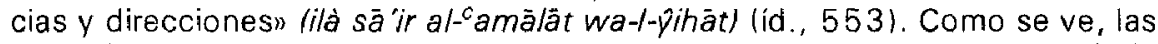
expresiones son muy semejantes, aunque revelan matices en el campo de la exportación y su forma de difusión.

También se exporta el hierro excelente de Constantina (Sevilla) «a todas las regiones de Al-Andalus" (yatayahhazu bi-hi ilà ğamitc aqtār Al-Andalus) líd., 574). "A todas las regiones de la tierra" (ilà pamí aqtār al-ard!) se exporta también el mercurio de Almadén lid., 581) y ua todas las direcciones" (ila kull yihăt) la cerámica dorada de Calatayud (íd., 3544). "A muchas regiones" "se llevaw la tierra amarilla y roja de las minas de Lorca (tuhmalu ilà katür min al-aqtär) (id., 561-562). En cambio se emplea el verbo "extenderse" (camma) para la exportación del papel de Xàtiva (Játiva) "a los Orientes y los Occidentes" (yu- 
'amm al-mašãriq wa-l-magărib) (íd., 556) y para la de la cerámica de Quesada (Jaén) en Al-Andalus y también el Mágreb (íd., 569 ).

Finalmente, hay que mencionar la exportación de dos productos que también menciona Al-Idrisi en su texto sobre Alicante, aunque en el caso alicantino no diga expresamente que se exporten. Elogia la extraordinaria calidad de los higos de Málaga uque se llevan a tierras de Egipto, de Siria y Palestina y de Irak v hasta llega quizá a la India" (vuhmalu ilà bilàd Miṣr, wa-š-Šàm wa-l-c/rāq warubba-mā wașala ilà al-Hind) (íd., 565) y las pasas de Jete, cerca de Almuñécar, que "se exportan a todos los países de Al-Andalus" (wa-yatayahhazu bi-hi ilà kull al-bilād al-andalusiyyal (íd., 564-565).

Con este panorama de las exportaciones explícitamente mencionadas en los textos de Al-Idrisi sobre Al-Andalus se comprende mejor la importancia nada pequeña que da el geógrafo a la producción de esparto de Alicante y a su exportación marítima.

El uso del verbo yatayahhazu indicaría, por comparación con el caso del coral de Ceuta, que no se exporta el esparto en estado bruto, sino elaborado. Hay que recordar que el esparto es la materia prima para varios grandes sectores uindustriales» en la Edad Media: el calzado (las alpargatas, en sus múltiples formas), el mueble (las esteras, en mezquitas, suelo de casas y lecho), el transporte (espuertas), etcétera.

La palabra "esparto" (al-halfä) no plantea ninguna dificultad. Su producción en la región (Cartagena, Crevillente, Novelda...) está atestiguada desde la Antigüedad hasta nuestros días. Eso obliga a plantearse si en este campo, como en otros de la descripción de Al-Idrisi, Alicante representa además de la ciudad también la región. Hay que advertir también que Al-Idrisi no menciona la producción de esparto de ninguna otra ciudad o región de Al-Andalus, ni siquiera de Cartagena, la antigua Cartagena Spartaria de los romanos, llamada por los árabes también udel esparton IQartayanna al-halfä').

\section{Productos de huerta: frutas, legumbres, uvas e higos}

Después de mencionar las exportaciones de esparto, Al-Idrisi enumera otras producciones agrícolas de Alicante, antes de pasar al valor estratégico de sus fortificaciones, a la construcción de las naves $y$ a la situación geográfica de Alicante. Dice que whay en ella frutas y hortalizas en cantidad y también higos y uvas" (wa-bi-hā fawākih wa-bagl katür wa-tin wa-a'nāb) líd., 558).

Antes de entrar en el análisis semántico de cada palabra de la enumeración y de comparar ese texto con otros paralelos de la descripción de Al-Andalus por Al-Idrisi, conviene reparar en algunas características de esa frase en árabe.

En primer lugar, se trata de cuatro productos alimenticios diversamente calificados: de las frutas y legumbres se dice que hay "mucho" (katir), cosa que no se dice de los otros dos productos alimenticios, los higos y la uva.

Pueda ser que no se trate sólo de una cantidad diversa de producción, al menos proporcionalmente. La fruta y las legumbres parecen ser productos de regadio, de huerta, mientras que la uva y la higuera pueden darse también en secano. Por otra parte, parece que las frutas y lequmbres son de consumo rápi- 
do y no se conservan - ya veremos que se tratá probablemente de legumbres verdes, no secas-; se suelen mencionar en las ciudades de Al-Andalus, en el texto de Al-Idrisi, para indicar la riqueza de una ciudad, de su gastronomía y de lo bien que se vive en ella. Por eso q'dizá haya de traducirse el "mucho" (katìr) por "abundante»: como no se exportan esos productos, su abundancia es relativa, proporcionada a una ciudad pequeña y a su relativamente escasa población.

Higos y uvas pueden exportarse, más o menos lejos. Los higos se secan y dan un apreciable alimento azucarado para los períodos en que el cuerpo necesita más calorías (invierno, mes de ayuno diurno del Ramadán). Las uvas dan pasas y vino, productos también transportables, como se verá.

Sin quęer apurar demasiado el análisis lingüístico de la enumeración, hay que advertic esos matices en el orden de esos cuatro productos.

También hay que advertir que son muchos los productos expresados. En otras ciudades o regiones de Al-Andalus, Al-idrisi no suele ser tan prolijo y detallado.

Finalmente, hay que advertir que el texto no habla más que de la ciudad de Alicante y su contorno (los otros puntos de referencia en la descripción son Denia, Bocairente, Elche, Orihuela y Santa Pola). Por tanto, si dice "hay en ella» (wa-bi-hā) se refiere a la ciudad propiamente dicha y su alfoz, el actual Camp $d$ 'Alacant. Eso limita prácticamente su producción agrícola a la huerta periurbana -el barranco meridional o actual barrio de la rambla de Méndez Núñezy a las zonas irrigadas por el agua sacada del río Monnegre, al norte de la ciudad -actuales términos municipales de Mutxamel, Sant Joan, El Campello y parte del de Alicante, en la zona de La Albufereta y playa de San Juan.

\section{Las frutas}

Las "frutas" (fawàkih, plural de fàkiha) de las que habla Al-Idrisi, no son probablemente frutas secas, sino jugosas y maduras. La raíz árabe indica gusto, agrado, placer, diversión y hasta broma (Kazimirski, II, 624-626). Al igual que las verduras, que se mencionan a continuación, evocan jardines y huertas, vida humana sana y equilibrada, alimentación rica y variada. Más que una información de tipo comercial, Al-Idrisi daría aquí un índice de nivel y calidad de vida urbana. Es muy posible que él mismo hubiera estado en Alicante, como dice expresamente de la región de Lisboa (ed. Dubler, 547). La observación de la producción de frutas es un dato muy subjetivo y de experiencia, sea suya o de sus informantes.

De otras ciudades y regiones de Al-Andalus menciona también Al-ldrisi los frutos, pero con más calificativos. También están acompañados de otros productos alimenticios vegetales que se mencionan en el texto sobre Alicante.

De Orihuela dice que tiene frutas innumerables (wa-bi-hā min al-fawākih mā lã tahșill la-hu) (íd., 558). De Mondéjar (Almería) que tiene toda clase de frutas según la estación (íd., 566). Tambiěn Coria, en poder ya de los cristianos, tiene "muchas clases de frutas" (așnāf min al-fawäkih katüral, especialmente viñas e higueras (íd. 547). Almuñécar tiene casi todas las clases de frutas (fawākih yamma) (íd., 564) y el río de Almería las produce con abundancia $\checkmark$ baratas (íd., 562). Entre la abundante producción alimenticia de Evora - ce- 
reales, carne - figuran ay además legumbres y frutas" (wa-sā'ir al-buqül wa-lfawākih) (íd., 544-545).

\section{Las legumbres}

El colectivo "legumbres" (baql) tiene en árabe al mismo tiempo un significado claro e impreciso. Se refiere en general a toda planta cultivada, herbácea, con hojas verdes. Pero no es fácil saber qué productos están excluidos de esa categoría.

En Al-Idrisi sólo se menciona en Alicante y, en plural, en el ya referido texto sobre Evora.

La reciente publicación de un libro de dietética árabe, del polígrafo granadino del siglo XIV, Ibn Al-Jatib (VAZOUEZ DE BENITO, M. C., Libro del cuidado de la salud durante las estaciones del año o "Libro de la Higiene», de Muhammad b. ${ }^{c}$ Abdallāh b. Al-Jațib. Salamanca, 1984), puede permitirnos conocer to que los árabes de Al-Andalus, al igual que Al-Idrisi en el siglo Xll, entendían por hortalizas o legumbres (buqül).

En efecto, al tratar de las propiedades de los diversos alimentos, trata de las hortalizas, curiosamente después del capítulo de las frutas (fawākih) -como Al-ldrisi-, de las que dice que «las uvas y los higos, que son los señores entre las frutas" (al-canab wa-t-tīn wa-humà sayyidä al-fäkiha) (o. c., pp. 55 árabe, 124 castellano). Es curioso que aunque hable en un mismo capítulo de todas las frutas, hace dos apartados diferentes, uno para las frutas verdes lfawàkih) (uvas, higos, dátiles, membrillos, peras, manzanas, granada, melocotón, albaricoque, ciruela, azufaia, toronja, acerola, mora, ciruela, plátano) y otro para frutas secas (lubüb) (nuez, avellana, almendra, pistacho, bellota, castaña) (íd., 56 á., 126 c.). Eso indicaría que la referencia alicantina no comprendería quizá a estos frutos secos.

Pero la lista de hortalizas es clara: lechuga, lengua de buey, achicoria, armuelle, espinaca, verdolaga, acelga, coliflor, calabaza, berenjena, ajo, cebolla, nabo, zanahoria, alcachofa, cardo, hojas de loto, trufa, setas, cohombro, pepino, melón, estos tres últimos en medio entre frutas y hortalizas, según lbn AlJatib. También relaciona con las hortalizas lo que M. C. Vázquez de Benito traduce como ucondimentos" (kawāmij): aceitunas, lima, rábano, zanahoria, flor de nuez moscada, alcaparra, condimento de mostaza y pasas. Evidentemente, la mención de Al-Idrisi no quiere decir que todos estos productos se dieran en Alicante, pero el hecho de que mencione especialmente esta producción alicantina indicaría que la huerta de Alicante produciría con relativa abundancia algunos de estos productos alimenticios.

\section{Los higos}

El "higo" como colectivo (tīn) o como "árbol de higo" (šayar at-tīn) figura como producto de muchos lugares de Al-Andalus, según Al-Idrisi, pero sus mayores alabanzas se dirigen a los higos de Málaga o "higos de Reyo», famosos con ese nombre y ya mencionado producto de exportación, hasta la India (íd., 570$)$.

También hay higos e higueras en Coria, Marbella, Jerez, Faro, Silves, Denia y Orihuela (id., 547,570,570,573,543,543,557,559). En estas dos ciudades se les menciona con las "viñas" (kurüm). 


\section{La uva}

Al-Idrisi menciona literalmente las "uvas" $\left(a^{c} n a \bar{a} b\right.$, plural de $\left.{ }^{c} a n a b\right)$, mientras que en otros lugares habla de "viñas" (kurüm) y una vez, en el caso de Jete ya citado, entre las exportaciones andalusies, de "pasas" (zabib), término que también puede aplicarse a los higos secos (íd., 564-565).

En realidad, de la misma planta pueden sacarse las uvas frescias, las pasas secas y el vino líquido y fermentado. Se puede con fundamento interpretar que el término empleado por Al-Idrisi para Alicante sea un eufemismo para designar el vino, licor prohibido por el Islam, salvo en casos de medicación, pero conocido como euforizante y como tema poético.

Las "uvas" se mencionan poco en Al-Idrisi: en Faro hay mucha "uva e higo" (katirat al-acnäb wa-t-tin) (id., 543) e ibiza es uuna isla hermosa, abundante en viñas y uvas" (yazira hasana katirat al-kurum wa-l-a $n a \bar{a} b$ ) (íd., 582). En este caso la duplicidad de productos nos inclinaría en favor del vino alicantino. Las "viñas» (kurüm) se citan en otros lugares de la Península: Burriana, Denia, Orihuela, Priego, Jerez, Coria, Montemar, Guadalajara, Daroca y Hornachuelos líd., 556, 557, 559, 571, 523, 547, 547, 553,554, 574).

Resulta curioso que después de la conquista, en 1259 , Alfonso $X$ de Castilla da normas comerciales para Alican te sobre "figos et azebib", higos y pasas, así como sobre "esteras d'alfa" y "camas desparto", lo que indica continuidad en la producción de los productos mencionados por Al-Idrisi, un siglo antes (ESTAL, J. M. del, Documentos inéditos de Alfonso X el Sabio y del Infante su hijo Don Sancho. Estudio, transcripción y facsímiles, Alicante, 1984, pp. 181, $182,229,2321$.

\section{Una fortaleza de difícil acceso}

Las descripciones urbanísticas de Al-Idrisi suelen incluir casi siempre una mención de sus elementos defensivos y militares: murahlas (sür), castillos (hisn) fortalezas (qasaba), torres (buny), miradores (maraya, näzür), plaza fuerte (qa $\hat{f}_{a}$ ), etcétera. Es evidente que los términos castellanos no se corresponden con exactitud con los árabes y que habría que hacer un estudio específico de la terminología militar de Al-Idrisi para comprender bien la clasificación que hace de las fortificaciones militares de Al-Andalus.

En Alicante no habla, como lo hace de otras ciudades, de las murallas ni de la situación particularmente estratégica de la ciudad. En cambio si se detiene, con relieve poco habitual en él, en la situación de su alcazaba (qașaba), que no califica de simple castillo (hișn) o de conjunto de castillos (husüuni), como lo hacen otros autores árabes. Aunque a veces estos términos parecen equivalentes entre sí o con las alcalas (qafa o su diminutivo qulal ${ }^{2}$ ) (Kazimirski, 11,803 ), en Al-Idrisi hay una gran diferencia: la qasaba forma parte de un conjunto urbano del que constituye la parte militar, mientras que el hisn tiene entidad urbanística propia y reúne en sí la población del lugar, evidentemente mucho más reducida. Esto es lo que puede deducirse del cotejo de la descripción de la alcazaba de Alicante con la de otras ciudades mencionadas por Al-idrisi.

Tienen alcazaba ciudades marítimas como Almería, Lisboa, Denia, Málaga, Vélez-Málaga (aunque diga que es maraya y hișn) (ed. Dubler, 562, 547. $557,570,565)$. También se mencionan las de otras ciudades: Mérida (aun- 
que sus palacios o qușür estén derruidos), Toledo, Jaén, Orihuela y Granada (íd., 545,551,568,558,569). Xàtiva es la única de la que dice que utiene alcazabas ejemplares por su hermosura y fortaleza" (mádina šātiba... yudrabu bi-hä al-matal fi l-hasan wa-l-manca) (íd., 556).

En realidad, el adjetivo correspondiente a "fortalezan que también se aplica en Al-Idrisi a la alcazaba de Alicante (qasaba manīal, "alcazaba fuerte", se refiere a la principal cualidad que tiene que tener una fortaleza: que sea inexpugnable. Así define Kazimirski ese adjetivo: inaccesible, inabordable, bien defendido, bien fortificado (II, 1158). Al-Idrisi se expresa con los mismos términos que en el caso de Alicante cuando habla de las alcazabas de Lisboa, Málaga y Denia (aunque en ésta añade - como en Alicante- el adverbio "mucho", piddan). La alcazaba de Almería es "famosa por sus defensas" (mašnüura bi-l-hișăna), la de Toledo por sus defensas y su inaccesibilidad (fi-hā hisāna wa-maña), la de Jaén es "de las más inaccesibles y defendibles" (min amna al-quisāa waahșani-hă) y la de Orihuela es uel colmo de lo inaccesible" (fi nihäva min al-im$\left.\operatorname{tin} \bar{a}^{c}\right)$.

- Todas estas expresiones, sobre todo si las comparáramos con expresiones semejantes que utiliza Al-Idrisi para otras clases de fortalezas, dan la impresión de que lo más importante de una alcazaba es que sea inaccesible: "fuerte" (plaza de guerra) sería equivalente a uinaccesible» (montaña), según la definición que da Dozy de manic (Supplément, II, 627). Pero hay que tener en cuenta la propia etimología de alcazaba, que viene de una raíz que significa "médula", "hueso central", "tubo de una caña, de una flauta", de ahí las acepciones generales, recogidas por Kazimirski, de «el centro, la parte principal, el corazón de un país", "ciudad, pueblo o aldea, según los países", "palacio, edificio principal de una ciudad, castillo, alcazaba, casa cuadrada" (II, 747).

La alcazaba es el centro del urbanismo árabe porque en ella reside la fuerza militar de la autoridad. Tener una alcazaba es tener un refugio fuerte y hacer fuerte a la autoridad. Por eso tiene que ser inaccesible y muy bien defendible. Ahora bien, como en la Edad Media el elemento fundamental de la estrategia defensiva es la situación de la fortaleza, por eso se insiste - pero es una noción secundaria - en esta situación.

Por eso se dice de Alicante que "tiene una alcazaba muy inaccesible y alta" (la-hā qașaba manīa cäliya yiddan), que está "en la parte más alta de un monte" (fi $a^{c} / a$ yaball, "al que se sube con fatiga y cansancio" (yus adu ilai-hi bimašaqa wa-ta $\left.{ }^{c} b\right)$. Esta última observación, muy subjetiva, podría indicar que el propio Al-Idrisi o alguno de sus informantes intentó la subida al actual castillo de Santa Bárbara de Alicante.

El que esté en la parte más alta de un monte es una referencia que hace también Al-Idrisi de otras fortalezas de Al-Andalus: por ejemplo, de Segura de la Sierra "en la punta de un monte" (fi ra's yabal), al igual que Alhama de Murcia y Carmona (íd., 560,566,572). Baena está uen la parte más alta de una alcudia o promontorio de tierra" (fi a'là kudya turāb) (id., 571). La alcazaba de Almería está "sobre un monte" (calà yaball (íd., 562) y de otras fortalezas se dice que dominan el mar. Pero sólo de Alicante se dice que la alcazaba está "en la parte más alta de un monte»: es una situación de castillos, como Segura, Alhama, Carmona y Baena.

Sólo de algunos castillos se dice también en qué consiste la dificultad en 
subir: la alcala de Bobastro es también sumamente inaccesible y bien defendida "subir hasta ella se hace por un camino difícil" laș-șucud ilai-hà calà taríq $s a^{c} b$ ) (id., 570); Mojácar es inaccesible a caballo y hay que hacerlo a pie líd., 5621; una montaña, entre Peñíścola y Burriana, exige también mucho esfuerzo, porque es paso obligado (íd., 555); pero es sobre todo el castillo de Tíscar, cerca de Baeza, "que supera a todos los castillos de Al-Andalus" (fãqa yam hușun Al-Andalus), en particular por su altura y porque sólo se puede subir a él por dos caminos muy distantes entre si y estrechos "como los lazos de las sandalias o el sendero de las hormigas", expresión en prosa rimada que se emplea también para expresar lo inaccesible de la alcazaba de Jaén (íd., 568, 568).

Finalmente, sobre esta situación estratégica de la alcazaba de Alicante puede aventurarse una hipótesis. Si los autores del siglo XI llaman a la fortaleza de Alicante hișn, mero castillo en alto, y Al-Idrisi, a mediados del XII, le llama qasaba, pero sin que pierda las características de altura de los castillos precedentes, es quizá porque en época almohade esa fortaleza tenia más categoría, militar y administrativa. Esto vendría confirmado por otros indicios urbanísticos, actualmente aún en estudio.

\section{Sus atarazanas para la construcción de naves}

Para terminar con su descripción de las características de Alicante, Al-Idrisi señala que "a pesar de su pequeñez, también se construyen en ella naves para largos viajes y barcazas" (wa-hiya aiḍan maca șugri-hā tunša u bi-hả al-maräkib as-safarivya wa-l-haräriq).

Sobre la pequeñez relativa de la ciudad de Alicante, ya se ha hablado anteriormente. Puede servir de referencia el mencionar las otras ciudades donde se construyen naves, según Al-Idrisi: en el puerto de Oașr Mașmüda, entre Ceuta y Tánger, "sse construyen naves y barcazas en las que se viaja a tierras de AlAndalus» (tunša"u bi-hi al-marākib wa-l-harārịq al-latī yusāfiru fi-hā ilà bilāo Al-Andalus) (id., 529); en Tánger hay "construcción de naves" (wa-bi-hã inša" al-maräkib) (íd., 529); en Algeciras se dice simplemente que "hay construcción, con salidas y entradas (de naves) » (bi-hā inša' wa-iq/ă wa-hațt! líd., 539 ); de Valencia se dice que hay "salida y entrada" (iq $\mathbf{a}^{c}$ wa-hatt), pero no que haya construcción (íd., 556); hay también "construcción" (inšă') en el río de Silves (íd., 543) y más aún en el de Alcácer do Sal, porque "es un río grande por el que suben muchos barcos y naves para largos viajes" (wa-huwa nahr kabir tus ${ }^{C} a d u$ fi-hi as-sufun wa-l-maräkib as-safariyyal y uhay mucha construcción” (wa-bi-hā al-inšà' al-kabir) (íd., 544); y sobre to do Denia y Tortosa (id., $557,555\}$. De Denia se especifica el origen y transporte de la madera, desde las montañas de Cuenca, por el río Júcar, Alcira y Cullera (íd., 560), y de Tortosa la buena calidad de esa madera. En Tortosa uhay construcción de grandes naves" (inß̌ă' al-maräkib al-kibärl. A Denia "vienen muchos barcos que en su mayoría han sido construidos alli porque es un lugar especializado en construir barcos" (hiya madina tusāfiru ilai-hã as-sufun wa-bi-hā yunša'u aktāru-hă lianna-hā där insă' as-sufun) (íd., 557).

Así como de Denia se dice que tiene mucho movimiento de barcos, en relación con sus atarazanas, y que de alli sale la escuadra contra los enemigos, nada de eso se dice de Alicante, como tampoco de Tortosa. En cambio, se habla del tráfico marítimo de Almería hacia Oriente, sin mencionar que tenga ata- 
razanas (íd., 562). Tampoco se menciona la construcción de buques en Cartagena, a pesar de que "tiene un puerto donde fondean naves grandes y pequeñas" (wa-la-hà minà" tursi bi-hā al-maräkib al-kibàr wa-ș-șigãr) (íd., 558 559). Pero es quizá un poco aventurado sacar conclusiones de las omisiones de Al-Idrisi, en general y en este caso particular.

Tampoco es fácil determinar las dos clases de naves a que se refiere el texto. Las "naves" (marākib) es un término general: las hay grandes y pequeñas, como hemos visto en el texto de Cartagena y en el de Tortosa, pero también sirven para puentes y atravesar ríos, como en Orihuela y Murcia (id., 558, 559). Parecen más pequeñas que los barcos (sufun, plural de safina), mencionados en Denia y en Alcácer do Sal, donde su mención acompaña a la de las unaves para largos viajes" (al-marākib as-safariyyal del texto sobre Alicante. El adjetivo, derivado de "viaje" (safar), indica probablemente que son naves sólidas, capaces de largas travesías.

Lo que hemos traducido por "barcazas" (haräriq), el "barque" de Dozy (Supplément, 1, 274) o "brûlot, navire à incendier", por etimología de esa raíz árabe que significa "quemar», según Kazimirski (1,411-412), es un término técnico, que Al-Idrisi sólo menciona al hablar de las atarazanas de Qașr Mașmuda y Alicante

Dozy traduce ambos términos, en el texto de Al-Idrisi sobre Alicante, como unaves para el comercio y barcas", sin más precisiones (DOZY-DE GOEJE, 235).

\section{La situación geográfica de Alicante}

En el conjunto de su libro, Al-Idrisi describe y sitúa al sur de Al-Andalus y parte del Mágreb septentrional en uel cuart clima" (al-iqlim ar-rābr $\bar{c}$ / y, dentro de éste, en ula parte primera" (a/-ỹuz' al-awwal) (íd., 525). Pero al referirse específicamente a Alicante, tiene dos géneros de coordenadas: el colocarla en una cora o división geográfico-administrativa (kūra); el señalar los caminos y distancias con otras poblaciones cercanas.

La división de coras de toda la Península de Al-Andalus, según Al-ldrisi, plantea numerosos problemas, que aquí ni se pueden mencionar. Bástenos aducir el texto, que está muy claro: después de mencionar la cora de Tudmir (con sus ciudades de Murcia, Orihuela, Cartagena, Lorca, Mula y Chinchilla), dice que "está contigua a la cora de Cuenca, en la que están Orihuela, Elche, Alicante, Cuenca y Chinchilla» (wa-yattașilu bi-küra Kuwanka wa-fi-hä Üriyüla wa-A/s wa-Laqant wa-Kuwanka wa-Saqurā) (id., 538). Le sigue la "región" (iq/im) de Argîra, de vocalización e identificación discutida, donde se encuentran las tierras de Xàtiva, Júcar; Denia y muchos castillos (husūn), y la región de Sagunto (Murbātar, o mejor transcrito en árabe dialectal Muro Vetere), donde están las tierras de Valencia, Morvedre, Burriana y muchos castillos.

No vamos, pues, a solventar todos los problemas que plantea esta división, que difiere muy sustancialmente de la que proponen otros geógrafos árabes y otras menciones medievales. Baste, con todo, con decir que las divisiones geográfico-administrativas pudieron variar mucho a lo largo de la historia de Al-Andalus y que la que trae Al-Idrisi, que posiblemente estuvo visitando esta región o tuvo información muy directa de ella en Sicilia, debe corresponder a la fecha de redacción de su libro, hacia 1754 , es decir antes de la primera épo- 
ca de gobierno de esos grandes reformadores en todos los campos que fueron los almohades. Pero los almohades, que se habian apoderado de la capital almorávide Marrákech en 1147 , pasaron a Al-Andalus ese mismo año $1147 \mathrm{y}$ se apoderaron de Sevilla (1147), Córdoba (1149), Badajoz (1150), Silves (1151), pero sólo recuperarán Almería en 1157 y los territorios orientales de Al-Andalus hacia 1172 . Por eso puede afirmarse que la división geográfico-administrativa que pudo conocer Al-Idrisi es pre-almohade y probablemente almorávide, diferente a la que refleja Al- ${ }^{C} U d$ dii, de principios del siglo. También parece que corresponde más a unos criterios geográficos, de distribución del espacio, que político-administrativos, en el desbarajuste que caracterizó la caída del régimen almorávide en la región.

Ya en un contexto más local, Al-Idrisi relaciona a Alicante con las poblaciones vecinas.

Está a 70 millas de Denia, "al oeste" de esta ciudad (garban/y upor vía marítima" (calà al-bahr) (íd. . 558). "Cerca de esta ciudad y al oeste (wa-bi-l-qurb min hädihil-madina wa-bi-l-garb min-hāl, es decir a oeste de Alicante, hay una isla - la actual Tabarca - que es un buen fondeadero para el enemigo y está a una milla de tierra firme, donde está el «Promontorio del Observatorio" (taraf annāzuúr), es decir el actual faro de Santa Pola, que está a 10 millas de Álicante. Entre Alicante y Elche, "por vía terrestre" Vbarran! hay "una jornada escasa" (marhala jafifa). Y, finalmente, entre Alicante $y$ "las gargantas de Palos" (hulüq bāluś) 57 millas. De ningún sitio en Al-Andalus da Al-ldrisi tantos de talles de tocalización.

\section{Conclusión}

Como conclusión de este estudio, volveremos a poner la traducción del texto de Al-idrisi, cuya lectura ha quedado evidentemente mejorada con los análisis a los que hemos sometido:

uDespués viene la cora de Tudmir, donde hay ciudades como Murcia, Orihuela, Cartagena, Lorca, Mula y Chinchilla.

Está contigua a la cora de Cuenca, donde está Orihuela, Elche, Alicante, Cuenca y Segura.

La sigue la región de Arguira, donde hay países como Játiva, Júcar y Denia, y muchos castillos.

Y desde la ciudad de Denia, antes mencionada, en la costa, hasta la ciudad de Alicante, al oeste, yendo por mar, hay 70 millas.

Alicante es una ciudad, pequeña, de buenas construcciones.

Tiene zoco, mezquita-aljama y otra mezquita con predicación.

Exporta esparto a todos los países del mar.

Hay muchas frutas y hortalizas, higos y uvas. 
Tiene una alcazaba, muy inasequible y elevada, en lo más alto de un monte, al que se sube con fatiga y cansancio.

En ella, a pesar de su pequeñez, se construyen naves para largos viajes y barcazas.

Cerca de esta ciudad, hacia el oeste, hay una isla llamada Planesa. Está a una milla de la costa. Es un buen fondeadero, que puede servir a las naves del enemigo. Está en frente del Promontorio del Observatorio.

Desde el Promontorio del Observatorio a la ciudad de Alicante hay 10 millas.

Desde la ciudad de Alicante, por tierra, a la ciudad de Elche, hay una jornada escasa.

Desde la ciudad de Alicante a las gargantas de Palos hav 57 millas." 